\title{
Early Sensitivity to Discourse-Level Anomalies: Evidence From Self-Paced Reading
}

\author{
Andrew J. Stewart, Evan Kidd, and Matthew Haigh \\ School of Psychological Sciences \\ University of Manchester, England
}

\begin{abstract}
Two word-by-word, self-paced reading experiments investigated the speed with which readers were sensitive to discourse-level anomalies. An account arguing for delayed sensitivity (Guzman \& Klin, 2000) was contrasted with one allowing for rapid sensitivity (Myers \& O'Brien, 1998). Anomalies related to spatial information (Experiment 1) and character-attribute information (Experiment 2) were examined. Both experiments found that readers displayed rapid sensitivity to the anomalous information. A reading time penalty was observed for the region of text containing the anomalous information. This finding is most compatible with an account of text processing whereby incoming words are rapidly evaluated with respect to prior context. They are not consistent with an account that argues for delayed integration. Results are discussed in light of their implications for competing models of text processing.
\end{abstract}

During reading, people create rich mental representations corresponding to the events described in a text. These representations are constructed using the semantic content communicated in the text, together with a reader's knowledge about the way in which such events typically unfold in the world. Much research in the text-processing literature has been directed toward determining the type of semantic information that is used in the construction of these models. There is strong evidence that these models involve some degree of perceptual simulation

Correspondence concerning this article should be addressed to Andrew J. Stewart, School of Psychological Sciences, University of Manchester, Oxford Road, Manchester, M13 9PL, England. E-mail: andrew.stewart@manchester.ac.uk 
(e.g., Barsalou, 1999; Glenberg \& Kaschak, 2002; Glenberg \& Robertson, 2000; Zwaan \& Taylor, 2006), and that they represent key aspects of the situation at hand (e.g., Therriault, Rinck, \& Zwaan, 2006; Zwaan, Langston, \& Graesser, 1995; Zwaan \& Radvansky, 1998). What is important to note about these frameworks is that they tend to focus on the information that is used to generate discourse-level representations, rather than on the time course of the mechanisms involved in the construction of those representations themselves.

In this article, we focus on the mechanisms associated with the construction of discourse-level representations. Specifically, we investigate the speed with which readers are sensitive to information in a text that is anomalous with respect to prior context. Understanding the time course of this sensitivity is important as evidence for, for example, an early sensitivity would support one class of processing models and rule out another. Whereas one general theoretical position in the literature allows for an early sensitivity (e.g., Myers \& O'Brien, 1998), a contrasting position does not allow for an early sensitivity, but rather predicts only a delayed effect (e.g., Guzman \& Klin, 2000). Later, we summarize and evaluate the empirical support for each of these perspectives.

In a series of influential studies, O'Brien and colleagues examined readers' sensitivity to discourse-level anomalies: Albrecht and O'Brien (1993) measured reading times to target sentences such as, "Mary ordered a cheeseburger and fries." The target sentence contained information that was either consistent or inconsistent with information previously mentioned in connection with the protagonist (e.g., Mary being a vegetarian or a fan of junk food). The authors reported a reading time penalty associated with reading information about a character that was incompatible with what the reader knew about that character. Similar results were obtained by O'Brien, Rizella, Albrecht, and Halleran (1998), who found an increase in reading times to two target sentences describing character attribute-related material that was inconsistent with the preceding discourse. Myers and O'Brien (1998) explained both sets of results in terms of resonance, a process that they suggested is initiated immediately. According to the resonance account, words are processed on an incremental basis, and the semantic information they contain resonates with concepts stored in the reader's memory that are associated with the unfolding situation model. A reading time penalty results when there is a clash in semantic features between the input and the information stored in memory. The work of O'Brien and colleagues used only whole-sentence reading time measures. As none of their studies measured the reading times of individual words, we cannot be sure that the effect that they observed occurred rapidly as readers encountered a mismatch, which would fit with a model of early integration, or whether it occurred downstream and thus reflected end-of-sentence, delayed, integration difficulties.

Recent work examining the time course of readers' sensitivity to discourselevel anomalies has produced conflicting findings. Guzman and Klin (2000) 
reported the results of four experiments that explicitly set out to examine how quickly readers displayed sensitivity to mismatching information. They examined the same kinds of inconsistencies that had been examined by O'Brien and colleagues. In their Experiment 1, they presented text to participants on a lineby-line basis. Their focus was on whether the reading time penalty previously reported by O'Brien and colleagues arose as soon as the anomalous information was encountered or whether it was delayed until end-of-sentence wrap up (cf. Just \& Carpenter, 1980). The sentence containing the inconsistent information spanned two lines of text. Guzman and Klin measured reading times for a target line (containing the inconsistent information) and a post-target line (up to and including the end of the sentence). They found that a reading time penalty emerged only on post-target line reading times (and thus not on reading times to the target line containing the inconsistent information). They took this as evidence that readers' sensitivity to information that mismatched preceding context reflected delayed processing (i.e., following the critical information). Two follow-up experiments using a different methodology (a probe task) produced data consistent with this position. They found no evidence that readers rapidly integrated incoming text with prior context. In an additional reading time experiment, Guzman and Klin reported that readers were sensitive to anomalous information when it appeared on a target line without a period, but only when the critical information did not appear at the end of the line. All of their data are consistent with an account whereby effects related to integrative processing (and reflecting a reader's sensitivity to anomalous material) occur only after a delay and following the critical material. They are not consistent with an account in which this sensitivity arises rapidly during processing of the critical material itself.

In contrast to the findings of Guzman and Klin (2000), Van Berkum and colleagues reported data suggesting that readers are rapidly sensitive to discourselevel anomalies: Van Berkum, Hagoort, and Brown (1999) reported the results of two event-related potential (ERP) studies that investigated semantic anomaly detection in written language comprehension using O'Brien and colleagues' consistency paradigm (Albrecht \& O'Brien, 1993; O'Brien \& Albrecht, 1992). Their goal was to determine whether the N400 effect, which typically arises in cases where there is low semantic fit between the input and the preceding sentence (e.g., Kutas \& Hillyard, 1984), can also be found for cases where there is low semantic fit between the input and preceding discourse. In their Experiment 1, participants were presented with sentences containing a critical word that was anomalous in light of preceding contextual information (e.g., the word slow in the sentence, "Jane told the brother that he was exceptionally slow," following a context that implied the brother had been quick). Relative to a condition where the target word was consistent with the preceding context (e.g., the word quick in the sentence, "Jane told the brother that he was exceptionally 
quick," following the same contextual passage), Van Berkum et al. (1999) reported an N400 effect following the onset of the target word. In a second experiment, Van Berkum et al. (1999) presented the same target sentences to participants without any context. The authors reported that the N400 effect disappeared in Experiment 2 and argued that its presence in Experiment 1 must therefore be due to the semantic mismatch between the anomalous target word and the preceding context. Van Berkum, Zwisterlood, Hagoort, and Brown (2003) conducted a similar pair of studies to those reported in Van Berkum et al. (1999); however, this time they studied spoken language comprehension. They found virtually identical effects. The apparent modality-independent nature of the N400 waveform associated with processing a target word in an anomalous discourse context is consistent with the predictions of the resonance account.

There is a clear contradiction in the literature between the findings of Guzman and Klin (2000) and of Van Berkum and colleagues (Van Berkum et al. 1999; Van Berkum et al., 2003). Indeed, there are a number of alternative explanations for the patterns of data reported by both groups of researchers. Guzman and Klin used a relatively coarse-grained measure of processing time that means that effects can only be localized to a particular line of text. In their Experiment 1, a reading time penalty related to a reader's sensitivity to anomalous information did actually arise during reading of the target sentence. In the context of reading times for an entire line of text, the magnitude of this reading time penalty (55 $\mathrm{ms}$ ) was not sufficiently large to be statistically significant. It is possible that a finer grained measure of processing (e.g., word-by-word reading) employing analysis regions smaller than entire lines of text would be sensitive to an effect of this size.

Van Berkum et al.'s (1999; Van Berkum et al., 2003) findings were based on ERP data. This method is highly sensitive to the time course of processing. However, a number of alternative explanations exist for the effects on which they base their account, which means that the conclusions drawn from the data may not be entirely robust. In Van Berkum et al.'s (1999) Experiment 1, the key comparison was between a target word that was different in each of the two experimental conditions (e.g., slow vs. quick). A comparison of the same target material across the two conditions would be stronger support for their position. Another, potentially more serious, matter to consider with the Van Berkum et al. (1999) study is that the critical target word appeared in sentence-final position roughly $44 \%$ of the time. The target word always appeared as one of the last three words in the critical sentence. Thus, it is possible that end-of-sentence, wrapup processing can account for their findings. Indeed, Guzman and Klin (2000) argued that the reading time penalty that they observed arose during delayed, wrap-up processing. The Van Berkum et al. (1999) data are compatible with this point of view. In addition, as they did not report by-items analyses, or analyses for only those materials where the target word did not appear in sentence-final 
position, it is possible that the N400 effect Van Berkum et al. (1999) reported was driven by that subset of items where the target appeared in sentence-final position. This would mean that any measurement of processing associated with that target word would also capture wrap-up processing. If this were the case, the results would not support rapid sensitivity to discourse level anomalies as much as they would end-of-sentence sensitivity associated with delayed processing. This would be consistent with an account of discourse processing in which higher level information was able to influence only delayed, wrap-up processing and is exactly what Guzman and Klin claim.

In the experiments that follow, we used word-by-word self-paced reading to examine the time course of readers' sensitivity to spatial inconsistencies (Experiment 1), and to character attribute inconsistencies (Experiment 2). Understanding the time course of sensitivity to these anomalies is important, as Myers and O'Brien's (1998) account allows for early sensitivity to these inconsistencies to arise. Evidence for early sensitivity would not be compatible with the position of Guzman and Klin (2000). However, as all of the target words examined by Van Berkum et al. (1999; Van Berkum et al., 2003) appeared toward the end of the target sentence, and as Myers and O'Brien's account was based on whole sentence reading time data, it is possible that inconsistency detection does not occur at an early point unless the inconsistent information can be processed during end-of-sentence wrap up (and would thus be compatible with the argument for delayed processing outlined by Guzman \& Klin).

\section{EXPERIMENT 1}

In Experiment 1, we examined readers' sensitivity to spatial information. O'Brien and Albrecht (1992) demonstrated a reading time penalty for sentences containing information that contradicted previously mentioned spatial information in a story. For example, in one of the experimental passages that we examined in Experiment 1, a singer ("Carly") is introduced as standing either to the side or at the centre of the stage. After several filler sentences, the critical target sentence, "After the first verse she moved to the centre of the stage where she would stay until the song ended," appears. According to O'Brien and Albrecht, a reading time penalty would be expected when this sentence is presented in the version of the story that introduced Carly as already standing at the centre of the stage. An early sensitivity account predicts that this penalty should be observable on reading times to the region of text containing the inconsistent information (i.e., the prepositional phrase, "to the centre of the stage"). Alternatively, under a delayed processing account, we would expect to observe a reading time penalty only toward the end of the sentence containing the critical material (i.e., on the post-critical region) and not on the region containing the prepositional phrase 
itself. This is what was reported by Guzman and Klin (2000). However, as noted earlier, it is possible that the measure of processing that they used was not sufficiently sensitive to detect an effect on the critical material. We based our experimental materials on those of O'Brien and Albrecht, but ensured that the critical region did not occur in sentence-final position. We constructed our materials so that the same target sentence could be compared across our two conditions, thus allowing us to rule out any possible effects driven by lexical differences between the words in our critical regions. In addition, we used wordby-word, self-paced reading to examine whether readers exhibit a reading time penalty for the region of text containing the anomalous information. An early sensitivity would be compatible with the account of Myers and O'Brien (1998), but not with the position put forward by Guzman and Klin.

\section{Participants}

Thirty participants from the University of Manchester population took part. All participants were native English speakers. They did not have a reading disability. They were paid $£ 5$ for participation.

\section{Materials}

Sixteen experimental passages were used in this study (see Table 1). The full set of materials for Experiment 1 can be found in Appendix A. There were two versions of each passage. Each passage was eight sentences long and divided into a number of sections: an introduction mentioning the spatial location (sentence 1), filler material (sentences 2, 3, and 4), the target sentence (sentence 5), the posttarget sentence (sentence 6), and two further filler sentences (sentences 7 and 8). These passages were used to create two lists using a latin-square design. We followed the convention of Albrecht and O'Brien (1993) by not including separate filler passages, per se, but counting the sentences that appeared between the spatial location information and our critical sentences as fillers.

TABLE 1

Example Material From Experiment 1

Carly stood at the side/centre of the stage to start the next song. This was her favourite song to perform. It was a difficult song and she was proud that she could sing it well. As it was her favourite, she always saved it for the end of a show. After the first verse she moved to the centre of the stage where she would stay until the song ended. Carly looked out into the audience and saw that people were singing along. She had always loved being able to entertain people. She felt so lucky that she was able to do what she loved for a living. 
The first sentence always described the main character as being in one of two locations (e.g., the side or centre of the stage). In sentence 5, the character is then described as moving into one of those locations (e.g., the centre of the stage). This target sentence is therefore consistent with only one version of the initial sentence in the passage. In the example in Table 1, this is the version where Carly is introduced as standing at the side of the stage. The target sentences remain the same across conditions, whereas the location of the character in sentence 1 is manipulated.

\section{Procedure}

Participants were presented with the experimental passages in a random order. Each participant was provided with verbal, as well as standardized written, instructions. These informed them that they would be presented with a number of passages on a word-by-word basis. To advance through the words in the passage, they were told that they had to press the "Next Word" button on a button box. This brought up the next word in the passage and blanked-out the previous one so only one word at a time was visible. Dashes were used to represent the rest of words in each passage. After each passage, participants were told a comprehension question might appear. Comprehension questions appeared on $25 \%$ of the trials. The questions did not probe information related to the factor we manipulated. If a question did appear, participants were told to answer it as quickly and accurately as possible, using the buttons marked "Yes" and "No" on the button box. Once the participant had answered the question (or pressed the "Next" button if no question appeared), the next trial began.

Participants completed two practice trials before beginning the actual experiment. One of the practice trials was followed by a question; the other had no question at the end. The practice trials were carried out so as to make sure that the participants were comfortable with the experimental setup and clear on what buttons should be pressed during reading of the materials and answering of the questions. At the end of the experiment, each participant was fully debriefed, thanked, and financially compensated.

The experiment was run using the E-prime programming software (MacWhinney, St James, Schunn, Li, \& Schneider, 2001). A button box recorded participants' reading times.

\section{Region Definitions and Analysis}

The data were analyzed for the total time (in milliseconds) participants took to read each region. The regions were defined as follows: In the target sentence, the critical region was the prepositional phrase. The post-critical region was the material that followed the prepositional phrase up to (and including) the 
TABLE 2

Mean Reading Times Per Region in Milliseconds, With Standard Errors (Experiment 1)

\begin{tabular}{|c|c|c|c|c|c|c|}
\hline \multirow[b]{2}{*}{ Variable } & \multicolumn{2}{|c|}{$\begin{array}{c}\text { Critical } \\
\text { Region in } \\
\text { Target Sentence }\end{array}$} & \multicolumn{2}{|c|}{$\begin{array}{c}\text { Post-Critical } \\
\text { Region in } \\
\text { Target Sentence }\end{array}$} & \multicolumn{2}{|c|}{$\begin{array}{c}\text { Post-Target } \\
\text { Sentence }\end{array}$} \\
\hline & $M$ & $S E$ & $M$ & $S E$ & $M$ & $S E$ \\
\hline Consistent & 643 & 48 & 1,137 & 95 & 2,492 & 200 \\
\hline Inconsistent & 712 & 58 & 1,180 & 98 & 2,668 & 189 \\
\hline
\end{tabular}

end of the target sentence. The final region was the post-target sentence. For the previous example, the region splits for each of the target and post-target sentences were as follows:

Critical region in target sentence: to the centre of the stage.

Post-critical region in target sentence: where she would stay until the song ended.

Post-target sentence: Carly looked out into the audience and saw that people were singing along.

\section{Results}

For the reading time data, analyses of variance (ANOVAs) were conducted treating participants $\left(F_{1}\right)$ and items $\left(F_{2}\right)$ as random factors.

\section{Region Analyses}

The mean reading times and standard errors for each region are presented in Table 2. For the critical region, there was an effect of condition- $F_{1}(1,29)=$ $5.794, M S E=12,860, p=.023 ; F_{2}(1,15)=5.102, M S E=6,978, p=.039-$ with this region being read more quickly in the consistent condition $(643 \mathrm{~ms})$ than in the inconsistent condition (712 ms). For the post-critical region, there was no effect of condition (both $F \mathrm{~s}<1$ ). For the post-target sentence, there was no effect of condition, $F_{1}(1,29)=1.576, M S E=294,470, p=.219 ; F_{2}(1$, $15)=1.806, M S E=243,528, p=0.199$. Comprehension question response accuracy was $88 \%$.

\section{Discussion}

We found evidence of a rapid sensitivity to the anomalous spatial information. This occurred on the critical region. There were no significant effects in the 
reading time data to subsequent regions. This is in contrast to the findings of Guzman and Klin (2000). In addition, it is also a slightly different pattern to that reported by O'Brien et al. (1998), whereby increases in reading times were observed both for a target sentence and a subsequent sentence. However, in the O'Brien et al. study, both of these sentences contained potentially inconsistent information. In our experiment, the post-target sentence was consistent with both versions of the experimental materials.

Crucially, the reading time pattern for the critical region in the previous experiment is similar to the pattern of ERP data reported by Van Berkum et al. (1999; Van Berkum et al., 2003). An early processing cost arose when anomalous spatial information was encountered. This is consistent with the claim that a discourse-level representation has a rapid constraining influence on incoming linguistic material. Our data are not compatible with an account of delayed processing of the type outlined by Guzman and Klin (2000).

Our finding that readers encode spatial information in their discourse models is compatible with a large body of research that has demonstrated the importance of spatial information in the construction and maintenance of a reader's discourse representation (e.g., Morrow, Bower, \& Greenspan, 1989; Rinck \& Bower, 2000). In a highly influential article, Morrow et al. demonstrated that, after memorizing the layout of a building and the location of objects within each room of that building, readers were sensitive to the likely proximity of those objects relative to a protagonist. Although this work demonstrates that readers keep track of spatial information, it does not address the time course of the updating of this information. The results of the experiment we reported earlier are compatible with an account whereby this updating occurs rapidly.

Spatial inconsistencies are a particularly strong type of semantic anomaly in that they describe impossible situations. It is possible that the reading time penalty we found for Experiment 1 reflected sensitivity to the impossible nature of the described event. If that was the case, then we would expect to find a weaker, later, or possibly non-existent effect for a semantic anomaly describing a possible, but unlikely, situation. In Experiment 2, we examined readers' sensitivity to information that was inconsistent with character attributes.

\section{EXPERIMENT 2}

Albrecht and O'Brien (1993) reported a reading time penalty associated with reading a sentence that contained information inconsistent with previously encountered facts presented in relation to a character in a story. A rapid sensitivity to anomalous information account predicts that there will be a processing cost associated with encountering this inconsistent information that is observable early (i.e., on the critical region). It also predicts that this cost will be similar 
to the cost we observed in Experiment 1 for spatial inconsistencies. If the effect reported in Experiment 1 reflected the operation of a general discourse-level processing mechanism, such as that proposed by Myers and O'Brien (1998), then we would expect Experiment 2 to provide us with similar results. However, if the effect reported in Experiment 1 simply reflected readers' sensitivity to the description of a situation that was impossible in light of the discourse at hand, then we would expect a much weaker processing cost associated with reading a description that is simply unlikely but still possible. A delayed sensitivity to anomalous information account predicts no early effect, but rather one arising on the post-critical region. As with Experiment 1, we constructed our materials so that the same critical region in our target sentences could be compared across conditions and did not appear in sentence-final position.

\section{Participants}

Thirty participants from the University of Manchester population took part. All participants were native English speakers. They did not have a reading disability. They were paid $£ 5$ for participation. They had not participated in Experiment 1.

\section{Materials}

Twenty experimental passages were used in this study (see Table 3). The full set of materials for Experiment 2 can be found in Appendix B. There were two versions of each passage. Each passage was seven sentences long and was divided into a number of sections: an introduction (sentences 1 and 2), information about the protagonist (sentences 3 and 4), a filler sentence (sentence 5), a target sentence (sentence 6), and a post-target sentence. These passages were used to create two lists using a latin-square design.

TABLE 3

Example Material From Experiment 2

Ben had always enjoyed going for a walk in the morning. This morning Ben bumped into Mrs Parker, a neighbour, who he had not seen in a while. SShe congratulated Ben on having just celebrated his 25 th birthday. Recently, he had begun to do additional fitness workouts before and after his walks.\}/\{She congratulated Ben on having just celebrated his 81 st birthday. Recently, he had started using a cane to help his walking and he now had to take numerous breaks on his walks.\} They began to talk about the weather when Ben saw a young boy lying hurt in the road. Ben quickly picked the boy up from the middle of the road and set him down on the pavement. There had been a lot of accidents on that stretch of road recently. 
Sentences 3 and 4 described some attribute information related to the character in the story. For the example in Table 3, one version of these two sentences describes the character as someone who is young and in good physical condition. In the other version, these two sentences describe the character as being old and in poor physical condition. Sentence 6 then describes the character behaving in a manner this is compatible with only one of these versions. This target sentence is therefore consistent with only one version of the earlier pair of sentences in the passage. In the example in Table 3, this is the version where "Ben" is introduced as being young and in good physical condition. The target sentences remain the same across conditions, whereas the attributes of the character in sentences 3 and 4 are manipulated.

\section{Procedure}

The procedure was the same as for Experiment 1. Comprehension questions appeared on $20 \%$ of the trials. The questions did not probe information related to the factor we manipulated.

\section{Region Definitions and Analysis}

The data were analyzed for the total time (in milliseconds) participants took to read each region. The regions were defined as follows: In the target sentence, the critical region was the verb phrase. The post-critical region was the material that followed the verb phrase up to (and including) the end of the target sentence. The final region was the post-target sentence. For the previous example, the region splits for each of the target and post-target sentences were as follows:

Critical region in target sentence: quickly picked the boy up from the middle of the road.

Post-critical region in target sentence: and set him down on the pavement.

Post-target sentence: There had been a lot of accidents on that stretch of road recently.

\section{Results}

For the reading time data, ANOVAs were conducted treating participants $\left(F_{1}\right)$ and items $\left(F_{2}\right)$ as random factors. 
TABLE 4

Mean Reading Times Per Region in Milliseconds, With Standard Errors (Experiment 2)

\begin{tabular}{|c|c|c|c|c|c|c|}
\hline \multirow[b]{2}{*}{ Variable } & \multicolumn{2}{|c|}{$\begin{array}{c}\text { Critical } \\
\text { Region in } \\
\text { Target Sentence }\end{array}$} & \multicolumn{2}{|c|}{$\begin{array}{c}\text { Post-Critical } \\
\quad \text { Region in } \\
\text { Target Sentence }\end{array}$} & \multicolumn{2}{|c|}{$\begin{array}{l}\text { Post-Target } \\
\text { Sentence }\end{array}$} \\
\hline & $M$ & $S E$ & $M$ & $S E$ & $M$ & $S E$ \\
\hline Consistent & 1,379 & 110 & 1,878 & 164 & 3,225 & 238 \\
\hline Inconsistent & 1,539 & 111 & 1,929 & 149 & 3,318 & 228 \\
\hline
\end{tabular}

\section{Region Analyses}

The mean reading times and standard errors for each region are presented in Table 4. For the critical region, there was a main effect of condition, $F_{1}(1,29)=$ 13.093, $M S E=29,672, p=.001 ; F_{2}(1,19)=8.158, M S E=26,919, p=$ .010 . For the post-critical region, there was no effect of condition (both $F \mathrm{~s}<1$ ). For the post-target sentence, there was no effect of condition, $F_{1}(1,29)=2.135$, $M S E=60,578, p=.155 ; F_{2}<1$. Comprehension question response accuracy was $94 \%$.

\section{Discussion}

Consistent with the results of Experiment 1, we found evidence of a rapid sensitivity to anomalous character attribute information. We observed a reading time penalty on the critical region associated with reading inconsistent character attribute information. This suggests that the effect we reported for Experiment 1 cannot be explained in terms of arising as a result of a reader's sensitivity to encountering material describing an impossible situation. The possible but unlikely situations we examined in Experiment 2 produced similar reading time penalties on the critical region. As with Experiment 1, we found no evidence of delayed processing costs and thus our data are not compatible with the account of Guzman and Klin (2000).

\section{GENERAL DISCUSSION}

In two experiments we found that readers consistently demonstrated rapid sensitivity to semantically anomalous information. This occurred for situations that were both impossible (spatial anomalies in Experiment 1) and possible but unlikely (character attribute anomalies in Experiment 2). Readers were quickly 
sensitive to anomalous information that resulted from a mismatch between the input and information provided by the preceding discourse.

Overall, our reading time data fit with the predictions of a processing model that argues for fast-acting integration of incoming linguistic material with an unfolding discourse model. This is consistent with the resonance account proposed by Myers and O'Brien (1998). It is not compatible with an account of delayed processing as proposed by Guzman and Klin (2000). However, as outlined earlier, the account of Myers and O'Brien was not based on data gathered using a temporally sensitive reading time measure. The work of O'Brien and colleagues (Albrecht \& O'Brien, 1993; O'Brien \& Albrecht, 1992) typically used whole-sentence reading time measures that do not provide the appropriate temporal grain with which to test the predictions of the resonance model. Guzman and Klin reported work that suggested that the processes associated with text integration operate only after a delay. We have argued earlier that the results they reported are open to alternative explanations as relatively coarsegrained processing measures were used to index online reading.

Although the position of Van Berkum et al. (Van Berkum et al., 1999, 2003) also argues for rapid sensitivity, they based their account primarily on data gathered using ERP measures. A number of alternative explanations for their pattern of results exist. The fact that their critical region appeared in sentence-final position on $44 \%$ of their experimental trials (and their failure to report $F_{2}$ values) means that the results they reported cannot unequivocally rule out a delayed processing account of text processing and integration. The studies we presented earlier involve a different (but still temporally sensitive) measure of processing (word-by-word reading) and, to avoid sentence wrapup effects, we ensured that our semantically anomalous information did not appear in sentence-final position. In addition, we compared the same critical region across experimental conditions for two different types of anomaly. Our results showed that with these controls an early processing cost associated with reading semantically anomalous input arose. The appearance of a reading time penalty in the pattern of reading times to the critical regions in our experimental materials argues against an account of processing whereby discourse-level factors exert an influence on interpretation only after a delay. Although Van Berkum et al. $(1999,2003)$ did not manipulate the type of anomaly with which readers were presented, the results from the experiments in this article show that anomalies related to both impossible and unlikely situations produce similar effects. We can rule out the account put forward by Guzman and Klin (2000), as we found clear evidence that readers were rapidly sensitive to discourse-level anomalies.

One question often raised in research examining the time course of processing is whether rapid effects are actually immediate effects or are effects occurring 
after some (small) delay. It is often difficult to clearly differentiate between these two positions. It could be argued that with a word-by-word presentation method it should be possible to localize effects on a particular word (rather than on a larger region of analysis comprised of several words). In practice, however, this is often quite difficult. It is certainly not a simple matter in the context of the anomalies we examined in the experiments previously reported. For the critical region of text, which is ultimately either consistent or inconsistent with preceding context, it is often not the case that one word determined the degree of consistency, but rather that there was a gradual accumulation of semantic information over the span of several words that resulted in the material being consistent or inconsistent. For this reason, we chose analyses regions that pooled reading times for several words.

Our findings are consistent with a model of discourse processing in which a reader's ongoing discourse representation constrains the incremental interpretation of an utterance. In contrast to the position typically adopted in sentence processing research, where the focus is on the influence of higher level factors on the interpretation of ambiguous input, our data show that an early influence of higher level information can also occur with respect to the processing of unambiguous material.

One reason that the text-processing and sentence-processing literatures have remained relatively separate, each adopting a different theoretical focus, is largely historical. Psycholinguists conducting research in the area of sentence processing have been influenced by linguistic theories, which propose a contextfree representation of the relations between words in an utterance. In contrast, psycholinguists conducting research into text processing have drawn heavily from theories of representation and memory, which instead place an emphasis on determining the type of semantic information contained within a text that is mentally represented. As texts are sequences of sentences, a research approach that better integrates the text-processing and sentence-processing areas is needed to allow research to more fully specify both the processes and representations involved in moment-by-moment comprehension.

\section{ACKNOWLEDGMENTS}

This research was supported by ESRC Grant RES-000-22-1601. We thank Ed O'Brien for supplying us with the materials examined in Albrecht and O'Brien (1993); Jos Van Berkum for supplying us with the materials examined in Van Berkum, Hagoort, and Brown (1999); and Matthew Cocksedge for assistance in data collection. We also thank Tony Sanford and the University of Glasgow language group, delegates at the Society for Text \& Discourse Annual Meeting 
Glasgow 2007, Michael Schober, and four anonymous reviewers for helpful comments on previous versions of this manuscript.

\section{REFERENCES}

Albrecht, J. E., \& O'Brien, E. J. (1993). Updating a mental model: Maintaining both local and global coherence. Journal of Experimental Psychology: Learning, Memory, and Cognition, 19, 1061-1070.

Barsalou, L. W. (1999). Perceptual symbol systems. Behavioral and Brain Science, 22, 577-609.

Glenberg, A. M., \& Kaschak, M. P. (2002). Grounding language in action. Psychonomic Bulletin and Review, 9, 558-565.

Glenberg, A. M., \& Robertson, D. A. (2000). Symbol grounding and meaning: A comparison of high-dimensional and embodied theories of meaning. Journal of Memory and Language, 43, 379-401.

Guzman, A. E., \& Klin, C. M. (2000). Maintaining global coherence in reading: The role of sentence boundaries. Memory \& Cognition, 28, 722-730.

Just, M. A., \& Carpenter, P. A. (1980). A theory of reading: From eye fixations to comprehension. Psychological Review, 87, 329-354.

Kutas, M., \& Hillyard, S. A. (1984). Brain potentials during reading reflect word expectancy and semantic association. Nature, 307, 161-163.

MacWhinney, B., St James, J., Schunn, C., Li, P., \& Schneider, W. (2001). STEP-A system for teaching experimental psychology using E-prime. Behavior Research Methods Instruments and Computers, 33, 287-296.

Morrow, D. G., Bower, G. H., \& Greenspan, S. L. (1989). Updating situation models during narrative comprehension. Journal of Memory \& Language, 28, 292-312.

Myers, J. L., \& O'Brien, E. J. (1998). Accessing the discourse representation during reading. Discourse Processes, 26, 131-157.

O’Brien, E. J., \& Albrecht, J. E. (1992). Comprehension strategies in the development of a mental model. Journal of Experimental Psychology: Learning, Memory, and Cognition, 18, 777-784.

O’Brien, E. J., Rizella, M. L., Albrecht, J. E., \& Halleran, J. G. (1998). Updating a situation model: A memory-based text processing view. Journal of Experimental Psychology: Learning, Memory, and Cognition, 24, 1200-1210.

Rinck, M., \& Bower, G. H. (2000). Temporal and spatial distance in situation models. Memory \& Cognition, 28, 1310-1320.

Therriault, D. J., Rinck, M., \& Zwaan, R. A. (2006). Assessing the influence of dimensional focus during situation model construction. Memory \& Cognition, 34, 78-89.

Van Berkum, J. J., Hagoort, P., \& Brown, C. M. (1999). Semantic integration in sentences and discourse: Evidence from the N400. Journal of Cognitive Neuroscience, 11, 657-671.

Van Berkum, J. J., Zwisterlood, P., Hagoort, P., \& Brown, C. M. (2003). When and how do listeners relate a sentence to the wider discourse? Evidence from the N400 effect. Cognitive Brain Research, 17, 701-718.

Zwaan, R. A., Langston, M. C., \& Graesser, A. C. (1995). The construction of situation models in narrative comprehension: An event-indexing model. Psychological Science, 6, 292-297.

Zwaan, R. A., \& Radvansky, G. A. (1998). Situation models in language comprehension and memory. Psychological Bulletin, 123, 162-185.

Zwaan, R. A., \& Taylor, L. J. (2006). Seeing, acting, understanding: Motor resonance in language comprehension. Journal of Experimental Psychology: General, 135, 1-11. 


\section{APPENDIX A}

\section{Experimental Materials Used in Experiment 1}

Carly stood at the side/centre of the stage to start the next song. This was her favourite song to perform. It was a difficult song and she was proud that she could sing it well. As it was her favourite, she always saved it for the end of a show. After the first verse she moved to the centre of the stage where she would stay until the song ended. Carly looked out into the audience and saw that people were singing along. She had always loved being able to entertain people. She felt so lucky that she was able to do what she loved for a living. Comprehension question: Did Carly hate entertaining people?

Julie was at the deep/shallow end of the swimming pool. She had been coming to the pool a lot recently in an effort to improve her fitness. She had also started jogging and taken out a gym membership. Her eating habits had also improved after a meeting with a nutritionist. Julie took a deep breath and started swimming towards the shallow end of the pool. She was determined to swim a further twenty lengths. She was going to Spain with her family in two months time. She wanted to be able to look back at photographs and be happy with the way she looked. Comprehension question: Was Julie going to Spain?

Sarah sat in the bright sunshine/cool shade in her garden reading magazines. She loved spending time by herself on her days off. Sarah loved her job but it involved a lot of traveling from place to place. She enjoyed being able to sit reading and not have to worry about being late because of bad traffic. After a while, Sarah decided to move her chair into the shade to cool down. She was very fair and knew that her skin did not react well to a long time in the sun. When she was younger Sarah ignored this in an effort to get a good tan. Now that she was older she had become more sensible. Comprehension question: Was Sarah reading magazines?

As Claire looked around the bathroom/kitchen of her new house she started to feel excited. The house was like a blank canvas and she was looking forward to decorating it. She already had lots of ideas for how she wanted it to look. Most of her ideas were inspired by her favourite home makeover programme. She went into the kitchen for some final measurements. Later she ordered the new furniture and chose the paint colours. She was keeping some of the furniture from the old house. She couldn't bear to part with her beautiful old bed. Comprehension question: Was Claire dreading decorating the house?

Rachel stood outside/inside the shop looking at the display of watches. She thought about how much she had bought on her last shopping trip. She realised 
she probably couldn't afford a new watch. Then she decided that as it was pay day soon she would treat herself. She walked inside the shop with her purse in her hand. When she got home she put the watch on straightaway. It was similar to one she had owned when she was younger. She decided she had definitely made the right choice.

Mary sat in the conservatory/garden feeling happy that the weather had been so warm recently. She had not been able to go abroad this year. The British summer normally disappointed her but the last few weeks had been glorious. She had even started to develop a tan. She walked into the garden and looked at the flowers. The new gardener had done a wonderful job. Mary was glad her sister had recommended him. Her sister always gave her good advice.

As John stood in the living room/kitchen he started to feel nervous. He had never been an impressive cook. He was starting to regret asking Sarah over for dinner. $\mathrm{He}$ also wished he had chosen an easier recipe. He walked into the kitchen and tried to calm down. He phoned his favourite restaurant to see if he could book a table for that night. Then he called Sarah and asked if she minded meeting at a restaurant instead. She was happy with the new arrangements and John was able to relax.

Lisa sat in the café/library thinking about her exams. The results were being posted the following day and she was nervous about how she had done. She always worried about exam results even though she never needed to. She was always at the top of the year. After a while she decided to go to the library to take out some books for her extra reading. On the way there she saw her friend Jenny. They were on the same course and started talking about the exams. They had both given similar answers and Lisa started to feel less nervous.

Susan stood inside/outside the museum waiting for her friend Joanne. She had been looking forward to seeing the new exhibition. All the reviews had been positive and she had heard many recommendations. Susan's parents had been very impressed and they were often hard to please. She went outside the museum and phoned Joanne to see why she was running late. Joanne was normally early for everything so Susan wanted to check she had remembered that they were meeting today. Joanne explained that she had been having car trouble recently and her car wouldn't start. She had decided to walk instead and arrived at the museum a while later.

Ben stood inside the flower/jewellery shop deciding what to buy for his girlfriend. His sister normally helped him make these decisions. This time he wanted to make the choice for himself though. After a lot of browsing he finally 
decided and made his purchase. He then walked into the jewellery shop to return something for his mother. He was really pleased with the gift he had chosen for his girlfriend. She always put a lot of thought into buying presents for him. He was pleased he had chosen something that she would really appreciate.

Margaret sat in the classroom/staff room marking her students work. She was very impressed with her new class so far this year. Not only did they all do well in lessons but they were all well behaved as well. She had never met such a polite group of children. When she finished marking she went to the staff room for the rest of the lunch hour. She was quite new at the school but had already become close to the other teachers. One of the female teachers was even in Margaret's year when she was at school. They would often sit and chat about their old teachers and classmates.

David stood in the bookstore looking in the classics/travel section. He used to work in the store on weekends when he was still at school. This was what had sparked his love of reading. He often came back to the store and he always bought something. He chose two books and then walked over to the travel section of the bookstore. He was planning a holiday to France with his two brothers. He wanted to be well informed about the area they were visiting. They were only going for one week and he didn't want to miss out on any of the interesting sights.

Jenny was in her bedroom/bathroom putting the finishing touches to her makeup. She was rushing because she was running late for a friends surprise birthday party. She had been in a meeting after work that had run on longer than had been expected. This had led to her being caught up in rush hour traffic. She heard her mobile phone ringing and ran into the bathroom where she had left it. It was her friend Juliet who had arranged the party. She told Jenny where and when to meet the rest of the group. Jenny realised that she had more time than she thought and managed to get to the party on time.

Dean was in the music store looking through the latest releases in the Pop/Rock section. He was buying a CD for his sister's birthday. His sister's boyfriend had told him of a new album she had said she wanted. Dean was glad of the advice because he always struggled to decide what to buy for her. He found the album and then went over to the Rock section to choose something for himself. He had been given vouchers for the store at Christmas and had not yet spent them. Looking through the rows of CDs he saw that there were many that he wanted to buy. He decided to buy his sister's present now and come back the week after when he would have been paid to buy something for himself. 
Paula was in the reptile/insect room at the zoo with her children. It had been a while since she had been on a day out with the children and was really enjoying herself. The children were having a good time as well. Each time they saw a different animal they excitedly told their mother everything they had been told about it at school. They moved on into the insect room next wondering what they would find in there. The children were looking forward to this room most of all. A boy in their class had bought in his pet tarantula the week before. They had begged Paula for one of their own but she had a great fear of spiders and couldn't bring herself to say yes.

Peter was waiting in the physics/chemistry department for his friend Ross. They hadn't seen each other for weeks and had arranged to meet for dinner. They had both been really busy recently with course essays and revision. Ross phoned Peter to tell him that his lecture had been moved to a different building. Peter picked up his bag and walked over to the chemistry department hoping that Ross knew a good restaurant nearby. They found that they had lots to talk about as they hadn't seen each other for so long. They talked about the exams and their plans for the summer. They arranged to meet up along with their other friends and go out again that weekend.

\section{APPENDIX B}

\section{Experimental Materials Used in Experiment 2}

Ben had always enjoyed going for a walk in the morning. This morning Ben bumped into Mrs Parker, a neighbour, who he had not seen in a while. \{She congratulated Ben on having just celebrated his 25th birthday. Recently, he had begun to do additional fitness workouts before and after his walks.\}/\{She congratulated Ben on having just celebrated his 81 st birthday. Recently, he had started using a cane to help his walking and he now had to take numerous breaks on his walks.\} They began to talk about the weather when Ben saw a young boy lying hurt in the road. Ben quickly picked the boy up from the middle of the road and set him down on the pavement. There had been a lot of accidents on that stretch of road recently. Comprehension question: Did Ben always enjoy going for a walk in the morning?

Kim had just started primary school. She would often tell her mum about the things she had done that day. \{Kim was always talking to her mum about animals and telling her how much she loved them. Every time she saw an animal she wanted to stroke it and take it home.\}/\{Unfortunately, Kim had always hated animals and was terribly frightened of them. Every time she saw an animal 
she ran away and began to cry.\} One day someone bought their pet dog to school. Kim started patting the dog immediately as it was very friendly. The dog belonged to one of her friends and was used to being around small children. Comprehension question: Was it a cat that one of Kim's friends brought?

Jane was meeting a friend for lunch at her local restaurant. She arrived early and looked over the menu while she waited. \{This was Jane's favourite restaurant because it served the most fantastic steaks. She was not a particularly healthy eater and had never worried about her diet.\}/\{This was Jane's favourite restaurant because it served the most fantastic food. She had been a strict vegetarian for ten years. $\}$ Jane's friend soon arrived and they chatted for a few minutes before ordering their meal. Jane ordered a large, juicy steak without hesitation as it was the restaurant's speciality. After her friend had ordered, Jane asked her what had happened in the last episode of Desperate Housewives. Comprehension question: Did Jane want to know what had happened in Desperate Housewives?

Naomi had been born prematurely but was now as healthy as any other child of the same age. One day, she was lying on the mat in the kitchen looking out of the window. \{Her mum was in the sitting room chatting on the telephone. Naomi was now five years old and very inquisitive.\}/\{Her mum was in the sitting room chatting on the telephone. Naomi was now two weeks old and very inquisitive.\} She could hear her mum laughing loudly when suddenly there was a crash from the sitting room. Naomi walked into the living room very quickly to see what had caused the noise. She started crying as the noise frightened her. Comprehension question: Did Naomi ignore the noise?

Rick had been looking for a hobby for a while. With his new job he had plenty of free time. \{Rick was a big man and had always tried to keep in shape by playing rugby and lifting weights. He loved tough physical contact sports which allowed him to compete against others.\}/\{Rick was unfit and wanted a hobby that didn't involve exercise. He hated energetic sports and preferred to play on his Playstation.\} While walking home one afternoon he noticed an advertisement for a new kickboxing class the local gym was running. Rick enrolled in the kickboxing classes without hesitation as he knew kickboxing was good for keeping fit. Rick felt a spot of rain and realized he had left his umbrella at work.

Adam was in the process of applying to universities. He needed to participate in more extra-curricular activities to improve his application form. \{Adam had always been outgoing and loved to talk and perform in front of people. He looked to see if his school had any activities he could take part in.\}/\{Adam had always been shy and he hated public speaking. He looked to see if his school 
had any activities he could take part in that didn't involve public speaking.\} When he checked his college's activities board, he saw an announcement for auditions for the spring play. Adam auditioned for the part of Romeo the next day. The spring play was usually the highlight of the school year.

Alex was on his way to a friend's house for a party. It was the first time in a while that Alex had visited because his friend lived quite far away. \{He enjoyed the journey to his friend's house as the mountain road was lined with ancient trees and great views. While speeding along the road at around 90 miles an hour, Alex was thinking about how much he enjoyed driving his new sports car.\}/\{It always took him a long time to drive to his friend's house because his car was so slow. While crawling along the country road, Alex was thinking about how much he disliked driving his old car.\} He didn't notice the police car that flashed its lights at him to stop. He was given a speeding ticket by the policeman. The bridge further along the road was closed so the policeman told him to follow the diversion signs.

Andy was not in the best of moods. His company had fired him because of cutbacks in funding. AAfter work he visited his local pub as he really needed a drink. He always came to this pub after work as he found it helped him to unwind after a tough day.\}/\{After work he visited his local pub although he didn't drink alcohol. Although he was a staunch Mormon and teetotaler, he found a few games of darts in the pub helped him unwind after a tough day.\} Andy opened up a newspaper and began to look for new jobs. He ordered a triple vodka on the rocks to drown his sorrows. The newspaper seemed to be full of potentially interesting jobs so he started to feel a bit more cheerful.

Tom had just been shopping and was on his way home. He did not have a car and so he had to catch the bus home. \{Tom had always found that he liked to live in his own little dream world. He was always getting told off at work for drifting off and daydreaming. $\} /\{$ Tom had been profoundly deaf since he was a child and couldn't hear a thing. It was not a problem for him as he was adept at sign language.\} When Tom was crossing over the road to the bus stop he did not notice the oncoming car. Tom heard the car honking its horn as it sped towards him. Luckily, Tom wasn't hit by the car but he was badly shaken by the experience.

Ed had recently graduated from university. In his final year he had become involved in numerous campus organisations. \{The organisations he was most involved in were the mechanical engineering and industrial clubs. He had never worried about protecting the environment and enjoyed driving his gas-guzzling car everywhere.\}/\{The organisations he was most involved in were Friends of 
the Earth and Greenpeace.\} He had always tried to protect the environment and so drove an eco-friendly car. One day, Ed was driving in his car and munching on a Subway sandwich. Ed chucked the empty sandwich wrapper out of his window as it was really messy. He was really proud of his car.

Dave's girlfriend told him she had a surprise summer holiday arranged for them. She had booked a week long break for them in Japan. (Dave loved to travel and enjoyed flying around the world. He was really surprised by his girlfriend's suggestion, but immediately said he would love to go.\}/\{Dave loved to travel but was terrified of flying. Although he was pleased about going on holiday he started to panic about the long flight that would be involved.\} When the leaving date arrived, Dave left his packing until the very last minute and they almost missed their plane. Dave was looking forward to the flight to Japan as they were traveling first class. The engines started and the plane rolled along the runway.

Last summer Jessica and her parents took a trip to France. She was glad they were going on holiday as it had been a busy year at University. \{Jessica had been learning French for years and spoke it fluently. She had always been good at languages and she impressed her teachers with her knowledge. $\} /\{$ Jessica specialized in mathematics and didn't really know much about other cultures. She had never had the chance to learn a foreign language at her school.\} When the family arrived in France one of the first things they did was go out for a meal together. Jessica ordered the meal in fluent French with a perfect accent when the handsome waiter asked what they would like to eat. The food was fantastic and lived up to everybody's expectations.

Emma loved to spend time at the seaside watching the waves crash against the rocks. She enjoyed the sun and the cool breeze that drifted in over the sea. \{Emma was a strong swimmer and worked every summer as a lifeguard at her local beach. She loved the feeling of being surrounded by deep ocean water and watching the waves make their way to the beach.\}/\{Emma had never actually learned to swim. She had nightmares about being surrounded by deep ocean water.\} One summer, Emma was staying with a friend who had a beach house by the ocean. Emma tried scuba diving in a nearby cove as this particular part of the beach was well known for diving. She was so jealous of her friend being able to afford a beach house.

Jennifer had been in a car accident many years earlier when she was a baby. Both her parents had been badly injured but luckily everyone survived. \{Jennifer had broken both of her legs in the crash. She had recently discovered that her father had been an Olympic archer when he was younger and had won many gold medals.\}/\{Unfortunately, Jennifer had been blinded in the crash. She had recently 
discovered that her father had been an Olympic archer when he was younger and had won many gold medals.\} Jennifer was also good at sport and had always wondered where her talent had come from. She had joined the archery club at school and won many competitions, much to her own amazement. Sport was something that she felt she had a natural ability for.

Darren had been badly injured while playing rugby at school. Although it had happened several years earlier he still needed regular medical check-ups. \{Darren's ankle had been badly broken when he had been tackled near the end of a game. The doctors were pleased with how it had mended and told Darren it was now as strong as ever.\}/\{Darren's neck had been badly broken when he had been tackled near the end of a game. He was now confined to a wheelchair.\} When Darren started at University he decided to join some clubs. He tried out for the rugby team when he arrived as the University was famous for producing great players. Several of the players on the English team had started out on the University team.

Louise was looking in the window of an expensive jewelry store on Bond Street. She really liked the expensive earrings she saw on display. \{Louise had won the lottery several months before and was now very wealthy. It wasn't unusual for her to spend many thousands of pounds in the space of an hour.\}/\{Unfortunately, Louise came from a poor family and could never afford such nice jewelry. She avoided credit cards because she was worried about getting into debt.\} She entered the shop and spoke to the jeweler behind the counter. Louise bought the expensive gold earrings with encrusted diamonds as she thought they were beautiful. She found it fun looking at all the items on display.

Henry really enjoyed eating out at weekends. One Saturday he decided to go and visit a new restaurant that had just opened in town. \{Henry really enjoyed all sorts of food and especially liked soup. The head chef was from Eastern Europe and apparently rather famous at home. $\} /$ \{Henry was allergic to red peppers so had to be careful to avoid any food that might contain them. The one time he had eaten red pepper by mistake he almost stopped breathing.\} The restaurant had a good selection of hearty, vegetable soups. Henry ordered the red pepper soup with garlic croutons as it had recently been awarded top marks by a famous restaurant critic. The restaurant really looked as if it was very popular that evening.

Joanne was really into music and listened to it all day while working. Luckily she worked at home so it didn't bother anyone else. \{She really liked pop music and hated most other types of music. Her favourite pop music was energetic and good for dancing to.\}/\{She really liked classical music but hated every type of 
pop music. She particularly hated electronic pop music.\} Each morning when she started work Joanne would play a CD from her vast collection to help her wake up. She enjoyed listening to energetic pop music first thing in the morning. She usually got a lot of work done before lunchtime.

Ahmed and his family had moved to Scotland from Pakistan when he was just a young boy. They moved into an area just east of Glasgow city centre. \{Ahmed was very religious and felt very loyal to his local religious community. He always went to the mosque and prayed several times a day.\}/\{Ahmed wasn't at all religious and felt more loyalty to Scotland than anywhere else. He never went to the mosque as he preferred to go and watch Rangers play at Ibrox.\} It was the first day of a religious festival. Ahmed rode to morning prayers at the local mosque on his bike as it was an important day. Most of the east end of Glasgow observed this religious tradition.

Jeremiah and his family were fasting for the weekend. They were very religious and were careful to uphold their faith. \{They always found fasting difficult and were glad the end was in sight. In fact, it was the last day of the fast and they would be able to eat at sundown that evening.\}/\{They always found fasting difficult but were never tempted to stop fasting early. It was the first day of the fast and they would not be able to eat for 36 hours.\} The sun sank beneath the horizon. Jeremiah made himself a peanut butter sandwich on brown bread as he always had a snack in the evenings. It was the middle of summer and the days were feeling really long. 